\title{
A Review on Consumer Health Information Technology Research in IS
}

\author{
Yafang Li \\ Washington State University \\ yafang.li@wsu.edu
}

\author{
Michelle Carter \\ The University of Alabama \\ mscarter3@cba.ua.edu
}

\author{
Robert E. Crossler \\ Washington State University \\ rob.crossler@wsu.edu
}

\begin{abstract}
While there is a rapid growth in the application of consumer health information technology (CHIT), its growth as an area of interest in IS research is still relatively slow. While there is great potential for research in this area, knowledge barriers to conducting CHIT research do exist. These include a lack of a clear definition of CHIT and lack of knowledge on the current state of CHIT research in IS. To overcome these barriers, we offer a definition of CHIT and then use that definition, together with the IT artifact perspective, to conduct a thematic analysis of CHIT research in the IS domain. We find that CHIT research spans all five IT views but to different degrees: nominal, proxy, and tool views are the most widely used perspectives. Based on our analysis, we suggest future research directions to enrich understanding of CHIT.
\end{abstract}

\section{Introduction}

The shift from "professional care" to "patient/consumer care" has prompted consumerization of health information technology [1]. Health industry stakeholders hope that the cost of health care can be reduced by empowering health consumers to be more proactive in their health maintenance, health management, and health promotion activities [1]. In support of that aim, numerous consumer health information technology (CHIT) applications have hit the market to fulfill consumers' health and wellness needs. These include Personal Health Records (PHRs), online health communities (OHCs), fitness wearables, healthcare apps, and so on [2].

The growth in CHIT applications has led scholars to expect a corresponding growth in the CHIT research. In 2010, a research commentary in Information Systems Research (ISR) predicted that the consumer perspective on health information technology (HIT) research would be the future of HIT research in IS [3]. However, while research on HIT research has been thriving in IS for some time, interest in the CHIT phenomenon has been far less than expected [4]. A recent review of HIT research in nine top IS journals from 2004 to 2017 found that, of the 202 papers collected, only $17.3 \%$ focused on consumer-related HITs [4]. Of these, the majority (71.4\%) were published between 2012 and 2017, leading the authors of this review to predict that research on consumer-related HITs will continue to grow in the near future [4].

Despite its promise, the considerable variation in terminology surrounding CHIT poses some challenges for IS researchers who want to conduct research in this area. First, the variety of terms used to represent HIT itself (e.g., e-health, m-health, telehealth, smart-health, etc.) are too generic and vague to allow researchers and practitioners to arrive at a shared understanding of HIT concepts [5]. Second, what constitutes (or does not constitute) CHIT is not yet clear. Though some definitions of CHIT have been offered in the domains of IS and health informatics (e.g., consumer E-health, consumer health IT application, consumer-oriented health information technology), no unifying name or definition for CHIT exists [6]. A clear, precise, and well-recognized articulation of CHIT is needed.

In pursuit of this aim, this study reviews the current state of CHIT research in the IS field. Our research question is, what is the nature of CHIT studies in IS? Through thematic analysis of the literature, we seek to provide a schema of extant work in the area and offer suggestions for future studies that can build cumulative knowledge.

This paper is organized as follows. First, we briefly review the current definitions of CHIT in the domains of IS and health informatics to propose a unifying definition of CHIT. Next, using this definition as a guide, we collect CHIT research from 11 high-impact IS journals [7] and 3 IS conferences proceedings. Then, following the principles of Braun and Clarke [8], we conduct a deductive thematic analysis on these collected papers. Orlikowski and Iacono's [9] IT artifact provides a theoretical framework for our analysis. Finally, we summarize trends of the current CHIT research and suggest some promising directions for future work. 


\section{Background}

\subsection{Defining Consumer Health Information Technology (CHIT)}

To understand the nature of CHIT research, we first need an understanding of what we mean by consumer health information technology. Thus, we conducted a brief review of existing CHIT definitions in health informatics and IS to arrive at a broad definition that could be used to scope this study. In health informatics, CHIT is described using terms such as "consumer health information technology" [10, 11], "consumer health information technologies" [12, 13], “consumer E-health” [14], "consumer-oriented health information technology" [15], and "personal health information systems" [16]. In the IS literature, we find terms like "consumer health IT" [17], "consumer health IT application" [18], and "CHI application" [6]. While these terms are sometimes used interchangeably, their descriptions vary to some degree. As such, no single term has yet been widely accepted and used across the health informatics and IS domains [6].

To arrive at a definition, it is necessary to understand differences and similarities among existing CHIT definitions by comparing them. In doing so, we found that current definitions incorporate five common components of CHIT, including (1) focus, (2) users, (3) technology, (4) goal or purpose, and (5) activities. Differences exist among definitions in their descriptions of these components. Only definitions of "consumer-oriented health information technology" [15] and "consumer health information technology" [10] include all five components.

For focus, descriptions include, "consumercentered" [10, 11]; “consumer-oriented" [12]; and "directly with the consumer" [18]. For users, terms used include "health consumer" [10]; "health consumers (i.e., individuals who seek or receive health care services)" [15]; “consumer” [12, 17]; "laypeople" [11]; and "health information users or consumers" [6]. Technology is described in terms such as, "tools, technologies, apps, or systems" [15]; "electronic technology" [11]; "any electronic tool, technology, or system" [6]; "computer-based systems" [13]; and "the collection of tools, technologies, and artifacts" [17]. For goal or purpose, descriptions include "promotion of health and health care" [10]; "promote health and well-being" [13]; "support health and health care management" [11]; "support their healthcare management task" [17]; and "support its users in managing their health information and health care" [18]. Finally, for activities, descriptions include "provide them with data, information, recommendations, or services" $[10,11]$, and "facilitate information access and exchange, enhance decision making, provide social and emotional support, and help behavior changes" [13].

After reviewing the descriptions of the various definitions, one existing definition (Tao et al.) [15] best encompassed the descriptions provided in other CHIT definitions. They define CHIT as "consumercentered electronic tools, technologies, applications, or systems that are interacted with directly by health consumers (i.e. individuals who seek or receive health care services) to provide them with data, information, recommendations, or services for promotion of health and health care" [15]. Nevertheless, we felt that the narrow articulation of "health consumers" as "individuals who seek or receive health care services" needed expanding.

In addition to individuals seeking or receiving healthcare, many researchers have expressed that "health care consumer" encompasses those who are not ill (i.e., seeking to maintain wellbeing), as well as patient caregivers [19, 20]. Therefore, we adapted Tao et al.'s [15] original articulation to incorporate a broader definition of health consumer. Thus, our proposed definition of CHIT is "consumer-centered electronic tools, technologies, applications, or systems that are interacted with directly by health consumers (i.e. individuals who use, have used, or are potential users, of health services including their family and carers) to provide them with data, information, recommendations, or services for promotion of health and health care". This definition provided a means to determine which articles to include in our review. Next, we briefly discuss the theoretical frame that guided our subsequent analysis.

\subsection{The IT Artifact Framework}

The IT artifact is the core subject in IS and how IS researchers engage with the IT artifact reflects the nature of IS knowledge [9, 21]. It follows that, since CHIT is an IT artifact, how scholars frame CHIT research is similarly influenced by current understanding of IS knowledge about how CHIT as an IT artifact is designed, deployed and used. Consequently, Orlikowski and Iacono's [9] views of the IT artifact provided a useful framework to guide our analysis.

Orlikowski and Iacono [9] proposed five broad categories of IT artifact used in IS research: tool view, proxy view, ensemble view, computational view, and nominal view. In the tool view, IS researchers focus on what the IT can achieve for its users. IT may be a tool for labor substitution, for enhancing productivity, for 
information processing, or for changing social relations [9]. In the proxy view, IT is captured "through individual perceptions, diffusion rates or dollar spend”, manifest as “technology as perception”, “technology as diffusion” or "technology as capital” respectively [9]. In the ensemble view, IS researchers focus on how IT is developed and used under the dynamic interactions between people and technology [9]. In the computational view, researchers focus on the computational power of IT and view technology as algorithm or as data modeling [9]. Finally, in the nominal view, technology is treated as background information or incidental descriptions [9].

\section{Methodology}

\subsection{Paper collection}

We conducted a literature review following procedures recommended by Webster and Watson [22]. To encompass a broad range of articles, we conducted a search of 11 high-impact IS journals [7] and the proceedings of three key IS conferences for the period, 2000 - 2018. Journals included, Decision Support Systems (DSS), European Journal of Information Systems (EJIS), Information Systems Journal (ISJ), Information Systems Research (ISR), Journal of the Association of Information Systems (JAIS), Information \& Management (I\&M), International Journal of Electronic Commerce (IJEC), Journal of Information Technology (JIT), Journal of Management Information Systems (JMIS), Journal of Strategic Information Systems (JSIS), and MIS Quarterly (MISQ). IS conferences were ICIS, AMCIS, and HICSS. The time frame was chosen to incorporate the fast development of the Internet and other technologies since 2000 .

We first searched on the following terms within keywords and titles of publication sources: "consumer health information technology”, “consumer health IT”, "consumer HIT", "health IT and consumers", and "health IT and patients". However, to avoid omitting related papers that capture the CHIT phenomenon, we mixed terms representing the health context (e.g., "health", "healthcare”, “medical”, "wellness", and "fitness) and those representing the users (e.g., "consumers" and "patients"). This search resulted in 999 papers. We excluded 673 irrelevant papers where scanning titles, abstracts, and descriptions of the IT artifact did not meet our definition of CHIT.

Another 150 papers were excluded based on four exclusion criteria that we determined prior to our search. We excluded (1) behavioral research that was not empirical; (2) editorial notes, research commentaries, review papers, instrument development, and taxonomy development papers; (3) research-inprogress papers, such as Emergent Research Forum (ERF) papers in AMCIS proceedings and short papers in ICIS proceedings; (4) conference papers, when a journal version of the same work exists and changes were trivial. This process resulted in 176 papers, comprising 36 journal articles and 140 conference papers.

\subsection{Thematic analysis}

Thematic analysis is "an accessible and theoretically flexible approach to analyzing qualitative data" [10]. We conducted a thematic analysis of the collected papers deductively, using Orlikowski and Iacono’s [11] IT artifact framework as a template.

We took a systematic approach to coding. First, we discussed our shared understanding of each IT artifact view [11]. For example, we determined that papers using technology acceptance models (e.g. TAM, TRA, TPB, UTAUT) belonged to the proxy view, as “technology as perceptions". The characteristics of IT artifact view were recorded in the code template, which helped us to code papers consistently. Next, 10 papers were selected randomly out of the sample and coded independently by the three authors. Then, the coding results were compared and discussed. For papers where codes differed, all three authors analyzed them briefly based on the research questions, research model and constructs, and then discussed until consensus was reached. Following procedures of Belanger and Crossler [23], we computed Cohen's kappa to test the inter-rater reliability, which was higher than $80 \%$. With this prior template in hand, one author took charge of classifying the remainder of collected papers.

\section{Findings}

\subsection{Descriptive analysis of the CHIT research}

For the 176 collected papers, we first categorized them into two groups based on publication outlets (i.e., journals or conferences). Since behavioral science and design science are two major paradigms in IS [24], we would expect researchers in each to approach CHIT with a different focus. To better depict the knowledge constituted by current CHIT research in IS, we, therefore, classified papers as behavioral science or design science papers. Table 1 shows the classifications of the collected papers.

Table 1 shows two clear trends. First, the number of CHIT studies presented in conferences is nearly four times as much as that published in journals. This trend 
may be explained in part by journals’ lower acceptance rates, the time it takes for work to appear in journals, and that conferences are often the birthplace for research on related to new and developing phenomena [6]. Second, there are nearly twice as many behavioral science papers as design science papers.

Table 1 CHIT article counts by outlet, by research paradigm

\begin{tabular}{|l|l|l|l|}
\hline Paradigm & \multirow{2}{*}{ BSR } & DSR & Total \\
\cline { 1 - 3 } Outlet & & & \\
\hline Journal & 28 & 8 & 36 \\
\hline Conference & 83 & 57 & 140 \\
\hline Total & 111 & 65 & 176 \\
\hline
\end{tabular}

Note: BSR=behavioral science research; DSR=design science research.

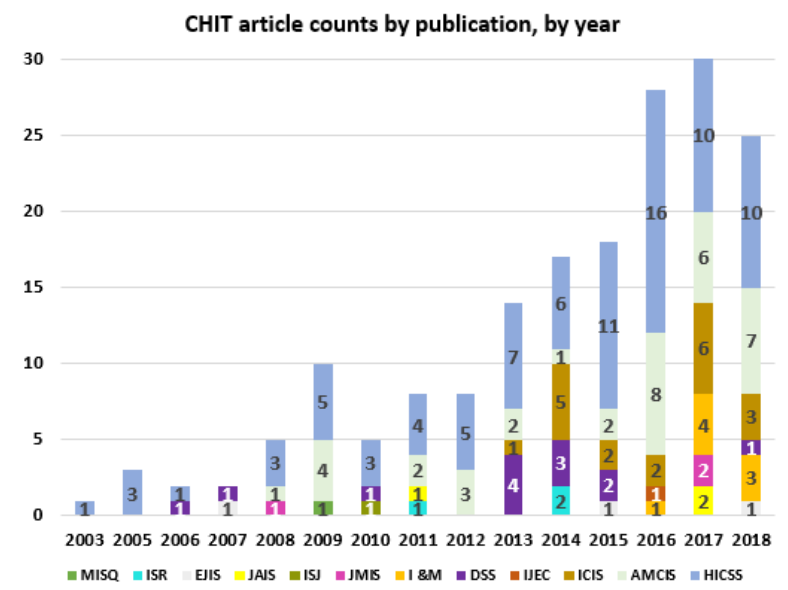

Figure 1 CHIT article counts by publication, by year

In our descriptive analysis, we also classified papers by publication and year to see overall trends of CHIT research in IS. As shown in Figure 1, among journals, DSS and I\&M have published the most CHIT research, with thirteen and eight publications, respectively. ISR, EJIS, JAIS, and JMIS each have three papers. MISQ, ISJ, and IJEC each have one. We did not find any CHIT research in JIT or JSIS. The number of CHIT papers in the three IS conferences varies greatly. HICSS proceedings include the largest number at 85, ICIS has produced 36, while AMCIS proceedings have only 19. Regarding publication year, CHIT research appeared in 2003 and has grown rapidly since 2008. Recent conference papers focus on new forms of CHIT such as health wearables [25] and fitness apps [26]. Due to their time lag, journal papers still focus on relatively old forms of CHITs, such as online health communities [27], health infomediaries [28], PHR [29], and telecare [30].

We also classified behavioral science research (Figure 2) and design science research (Figure 3) by publication and by year. We found the following trends regarding the CHIT behavioral science research in IS. First, CHIT behavioral science papers are published almost three times more frequently in conferences than in journals. Among journals that have published CHIT behavioral science research, DSS and I\&M have each published seven papers. EJIS, JAIS, and JMIS have published three, ISR has published two, and MISQ, ISJ, and IJEC have published one. For conference papers, 44 papers have appeared in HICSS proceedings, 24 papers in ICIS, and 15 papers in AMCIS. As Figure 2 shows, CHIT behavioral science research appeared in 2007. The two papers published in 2007 focused on patient portals [31] and health infomediaries [32].

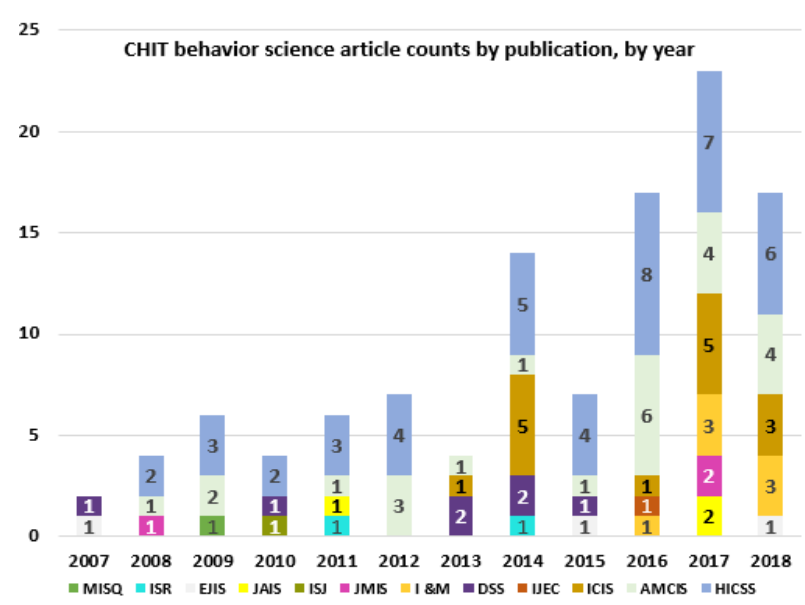

Figure 2 CHIT behavioral science article counts by publication, by year

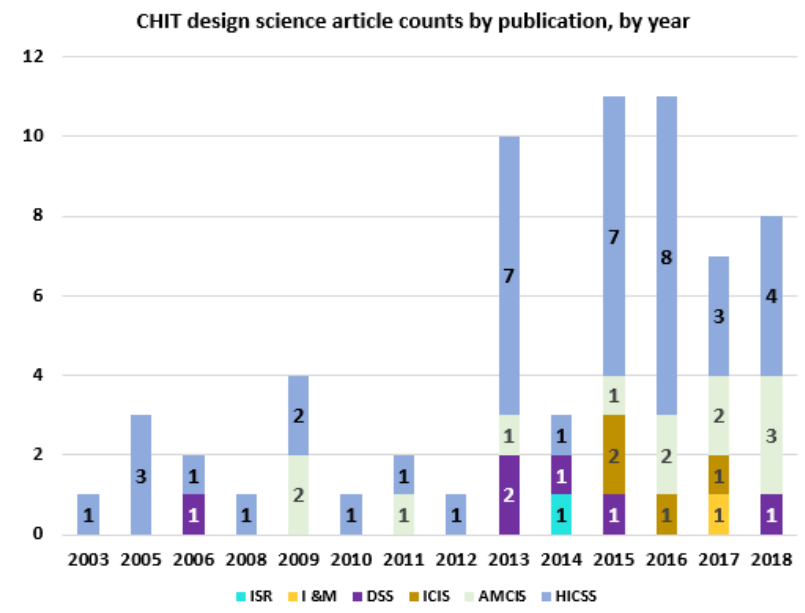

Figure 3 CHIT design science article counts by publication, by year 
CHIT design science papers are published eight times more frequently in conferences than in journals (Figure 3). For journal papers, DSS is clearly the most popular outlet with six publications. ISR and I\&M each have one. No design science papers were found in other journals. Surprisingly, this includes JIT, which has high interest in publishing design science work. Among conferences, 41 papers have been published in HICSS, 12 in AMCIS, and four in ICIS. This finding was consistent with our expectation that HICSS would publish more design science research than the other two conferences. CHIT design science research appeared in 2003 - four years ahead of behavioral science research - in a study to develop an agent-based smoking cessation message delivery system [33].

\subsection{The nature of the CHIT research}

To assess the nature of CHIT research, we next classified articles by their treatment of the IT artifact. According to Orlikowski and Iacono, the view of the IT artifact may be influenced by the research paradigm adopted [9]. For example, papers that take a computational view of IT tend to appear in design science paradigm [9]. Thus, to explore differences in treatment of CHIT as an IT artifact, based on research paradigm, we also differentiate papers by design science research and behavioral science research.

Table 2 CHIT as an IT artifact

\begin{tabular}{|c|c|c|c|c|}
\hline \multicolumn{2}{|c|}{ View of technology } & \multirow{2}{*}{$\begin{array}{l}\text { BSR } \\
2\end{array}$} & \multirow{2}{*}{$\begin{array}{l}\text { DSR } \\
12\end{array}$} & \multirow{2}{*}{$\begin{array}{l}\text { Total } \\
54\end{array}$} \\
\hline Tool & IP & & & \\
\hline & SR & 4 & 0 & \\
\hline & PRD & 11 & 25 & \\
\hline \multirow[t]{2}{*}{ Proxy } & $\overline{\text { DIF }}$ & 6 & 0 & \multirow[t]{2}{*}{40} \\
\hline & PCP & 34 & 0 & \\
\hline \multirow[t]{2}{*}{ Computational } & MOD & 0 & 7 & \multirow[t]{2}{*}{8} \\
\hline & ALG & 0 & 1 & \\
\hline \multirow[t]{2}{*}{ Ensemble } & STR & 1 & 0 & \multirow[t]{2}{*}{8} \\
\hline & ES & 7 & 0 & \\
\hline \multicolumn{2}{|l|}{ Nominal } & 46 & 20 & 66 \\
\hline \multicolumn{2}{|l|}{ Total } & 111 & 65 & 176 \\
\hline
\end{tabular}

Note: IP=information processing; $\mathrm{SR}=$ social relations; $\mathrm{PRD}=$ productivity; $\mathrm{DIF}=$ diffusion; $\mathrm{PCP}=$ perception;
MOD=model; ALG=algorithm; STR=structure; ES=embedded system.

As shown in Table 2, the nominal view, tool view, and proxy view are the most common perspectives of the IT artifact used in CHIT research, accounting for $37.5 \%, 30.7 \%$, and $22.7 \%$. In behavioral science research, the nominal view (41.5\%) and proxy view (36\%) predominate. In design science research, the tool view is most commonly used, accounting for $56.9 \%$ of the collected 65 papers. $30.7 \%$ of design science papers use the nominal view, while $12.3 \%$ of use the computational view.

4.2.1. CHIT as an IT artifact in behavioral science research. To further explore the nature of these CHIT papers, we summarize the common characteristics of papers under each type of IT view. Examples are provided to illustrate each view. Table 3 provides category justifications for CHIT behavioral science research.

Table 3 CHIT as an IT artifact in BSR

\begin{tabular}{|c|c|c|}
\hline \multicolumn{2}{|c|}{ View of technology } & Category Justification \\
\hline \multirow[t]{3}{*}{ Tool } & IP & $\begin{array}{l}\text { Making comments, reviews, } \\
\text { posting questions }\end{array}$ \\
\hline & SR & $\begin{array}{l}\text { Peer support relationships; } \\
\text { patient-doctor relationships, } \\
\text { patient satisfaction; patients' } \\
\text { trust in doctors }\end{array}$ \\
\hline & PRD & $\begin{array}{l}\text { Improving health outcomes; } \\
\text { reducing health costs, users' } \\
\text { health care information search } \\
\text { behavior; patient adherence }\end{array}$ \\
\hline \multirow[t]{2}{*}{ Proxy } & DIF & $\begin{array}{l}\text { Focus on how many people are } \\
\text { currently using IT and the } \\
\text { demographic trends }\end{array}$ \\
\hline & PCP & $\begin{array}{l}\text { Study the adoption and use of } \\
\text { CHIT based on some cognitive } \\
\text { theories, such as TAM, TPB, } \\
\text { and UTAUT, or by using } \\
\text { constructs such as intention to } \\
\text { use, perceived usefulness, } \\
\text { perceived ease of use, } \\
\text { perceived value, perceived } \\
\text { benefit, and perceived risk }\end{array}$ \\
\hline \multirow[t]{2}{*}{ Ensemble } & STR & Structurational analysis \\
\hline & ES & $\begin{array}{l}\text { Focus on utilization patterns of } \\
\text { CHIT among different users }\end{array}$ \\
\hline Nominal & \multicolumn{2}{|c|}{$\begin{array}{l}\text { CHIT as background information but the } \\
\text { focus is on something else }\end{array}$} \\
\hline
\end{tabular}


Under the tool view, CHIT is an information processing tool, a social relations tool, and a productivity tool. Health infomediaries and online health-care market communities are two examples of CHIT as an information processing tool. Yim et al. [34] studied how patients' postings in a health infomediary influence their likelihood of contacting a doctor. Liu et al. [35] studied how physician's appointments are influenced by a physician's online and offline reputation, as well as by a hospital's online and offline reputation. Online social platforms and OHCs are examples of CHIT as a social relations tool. These papers look at how CHIT changes peer support relationships [36] and the patient-doctor relationship [37]. For papers treating CHIT as a productivity tool, some focus on how the use of CHIT improves health outcomes, such as reducing body fat or improving physical fitness [26] or effecting mood changes, distress level, and detailed distress components [38]. Some focus on how CHIT help improve users' fitness activity accomplishments [39] and patient compliance [40]. Others examine how the use of CHIT reduces health costs [41]. Short Message Service (SMS) is a typical application of CHIT as a productivity tool for patient compliance.

Under the proxy view, research often focuses on individual perceptions of CHIT. In this stream, the adoption of CHIT (e.g. PHR, patient portals, mobile video consultation, wearable, and health robot) is studied widely using technology acceptance models, such as TAM, TPB, and UTAUT [31]. To add contextualized characteristics of CHIT, adoption models are integrated with health factors, such as health status, health need, health knowledge, health consciousness, health concern, physical disability, and health expectancy. Other research considers consumers' perceived value of PHR [29] and trusting beliefs about a health infomediary [32]. Papers viewing CHIT as diffusion focus on how many people are currently using CHIT and trends, such as demographic trends in consumer e-health adoption [42].

Under the ensemble view, CHIT has been viewed as structure, e.g., Boonstra and Van Offenbeek conducted a structurational analysis on a telecare program implementation [30]. When CHIT has been viewed as an embedded system, research has focused on utilization patterns of CHIT among different user groups, such as how the PHR feature use is influenced by patients' demographic characteristics [43].

Under the nominal view, CHIT provides background, but the focus is elsewhere. Research in this stream includes drivers of health information privacy concerns [44], PHI disclosure intention [45], leadership in a Facebook health support group [46], EHR persuasion strategies [47], factors impacting patient portal readiness [48], trust in online health information [49], trust in members of online health forum [50], individual provision of informational and emotional support in OHCs [51], and effects of patient consensus on treatment ratings in OHCs [52].

\subsubsection{CHIT as an IT artifact in design science} research. Table 4 shows category justifications for CHIT design science research. Under the tool view, 12 papers view CHIT as an information processing tool. Examples in this stream include research to develop design principles for learning health system applications [53] and research to design a personal health data dashboard to encourage self-reflection [54]. Twenty-five papers treat CHIT as a productivity tool, including work to design tools for improving medication adherence [55], for health intervention [56], and for appointment reminders [57].

\section{Table 4 CHIT as an IT artifact in DSR}

\begin{tabular}{|l|l|l|}
\hline \multicolumn{2}{|l|}{ View of technology } & Category Justification \\
\hline Tool & IP & $\begin{array}{l}\text { Design and develop CHIT } \\
\text { tools which change how } \\
\text { human process information }\end{array}$ \\
\cline { 2 - 3 } & PRD & $\begin{array}{l}\text { Design and develop CHIT } \\
\text { tools which extend and } \\
\text { enhance individuals' } \\
\text { ability to perform health- } \\
\text { related tasks, thus, to } \\
\text { improve health outcomes }\end{array}$ \\
\hline Computational & MOD & $\begin{array}{l}\text { Representing the social, } \\
\text { economic, and } \\
\text { informational aspects of } \\
\text { CHIT phenomena through } \\
\text { data modeling }\end{array}$ \\
\hline Nominal & \multicolumn{2}{|l|}{$\begin{array}{l}\text { Use CHIT as background but focus } \\
\text { on something else }\end{array}$} \\
\cline { 2 - 3 } & on algorithm to create \\
\hline
\end{tabular}

Under the computational view, Mujallid and Alghamdi [58] design an algorithm to facilitate reporting by patients or healthcare professionals of adverse drug reactions via Twitter. Seven papers view IT as a model, for example, proposing concepts of context and context-awareness in mobile patient monitoring [59], and developing a comprehensive diabetes information profile to prioritize information for diabetic patients [60].

Under the nominal view, design science research focuses on issues surrounding CHIT, such as the design of an evaluation framework for the quality of 
health website [61], a framework of topic analysis in an online health community [62], and exploring health characteristics for CHT user profiles and persona [63].

\section{Discussion}

\subsection{What has been done in CHIT research?}

Our review of CHIT research in IS provides the following key findings. First, with regard to the popular research topics, our analysis of the IT artifact views of CHIT research reveals that the nominal view, tool view, and proxy view are the most common perspectives of the IT artifact used in CHIT research.

In the proxy view, CHIT adoption is a dominant topic. Types of CHITs studied include, PHR, patient portals, mobile video consultation, wearables, and health robots, which are relatively new forms of IT to consumers. In contrast, when CHITs are familiar to consumers (e.g., SMS messaging and health infomediaries), the nominal view predominates. In this stream, privacy concerns and trust dominate behavioral science research. In design science, the nominal view focuses on designing quality evaluation frameworks for health information or for health websites. In the tool view, behavioral science research emphasizes CHIT' role in improving health outcomes, doctorpatient relationships, and patient-patient relationships. Design science research focuses on developing tools to change or extend the capability of CHIT to process health information or improve health outcomes.

Second, with regard to popular CHITs, we see a trend towards researching the CHIT in the context of mobile delivery platforms. Prior to 2008, CHIT research focused on a variety of CHITs where the internet was the delivery platform. Since 2014, apps that promote wellbeing (e.g., fitness apps, sleep apps) and fitness wearables (e.g., Fitbit) have begun to attract researchers' interest. Whereas, at the other end of the popularity spectrum, telecare and health robots are studied least frequently.

Third, regarding research topics around popular CHITs, we find that adoption, feature analysis, privacy policy, business model value and IS success are some common topics around PHR. Adoption, resistance, and patient portal readiness are important in the context of patient portals. Where there exists a relational aspect e.g., in OHCs, social media, and health infomediaries, key research topics include trust, privacy concerns, social support, knowledge sharing, and health outcomes. Regarding health apps, feature analysis, continuance, and health outcomes are emphasized. For wearables, which are still relatively new, adoption and privacy concerns are two main topics.

\subsection{What can be done in the future?}

Regarding new CHIT research, we encourage IS scholars to look at the following aspects. CHIT that delivers health services via mobile platforms or telecom platforms will continue to provide fruitful research opportunities. We believe that as wearables, health apps, and telecare become ubiquitous, new areas of investigation around these technologies will become necessary. While current research on wearables focused on adoption and privacy concerns, future research can work on use patterns, feature analysis, and effective use of wearables. For example, how will the materiality of wearables influence people to perceive health management activity and then influence their health outcomes? Some potential theoretical perspectives for these questions include affordance theory, empowerment theory, health behavior change theory, social cognitive theory, and others.

For health apps, current research mainly focuses on fitness apps, diabetes apps, and sleep apps. However, research on other types of health apps (e.g. symptom checkers, healthcare professional finders, selfdiagnosis, self-monitoring; medication reminders, and remote monitoring) is scant. Given that apps have many different functions, the research opportunities in the area of health apps are plentiful. As an example, it would be interesting to explore how "doctor on demand", an online diagnosis and treatment app may affect the reputation and economic returns of physicians? Additionally, what are the economic effects and health effects for patients? How will the "doctor on demand" app influence the quality of physicians' online and offline services? For remote monitoring apps, it would be fruitful to investigate whether the use of these apps leads to a shift in power dynamics in the doctor-patient relationship. How will patterns of health care professionals' practices change? For telecare, the question of how to expand the usage rate is challenging the industry. Research using theoretical frames such as persuasion strategy and user empowerment may shed light on promoting diffusion.

Given the amount of information contained in OHCs, how to manage, store, refresh, and provide access to this information become increasingly important areas for research. Some example questions include, how will newcomers to an OHC access and make best use of existing information? What strategies will an OHC have for displaying comments or reviews? How often should information change to retain users' interest in the OHC? What kinds of health information are more valuable to users and who gets to decide? What kinds of usage patterns exist for different kinds of users, regarding health information? How can an OHC deal with information overload from an 
emotional perspective? How do different emotions or psychological needs influence users' decision-making with respect to health advice in an OHC?

For behavioral science researchers, we encourage research that operates at different levels of analysis. In current CHIT behavioral science research, the individual is the dominant unit of analysis. Most papers focus on patients or consumers, and some focus on physicians. At this level, the role of individual family members and caregivers are also worthy to consider. Future CHIT research could also consider the role of social structures at the group level, organizational level, and society in promoting the diffusion of CHIT.

For design science researchers, it is promising to develop health information analysis tools regarding some contextual factors, whether for predicting symptoms or diseases, or for making health decisions. For example, questions of how to make personalized exercise recommendations based on consumers' mood, stress level, and work schedule are technical challenges for fitness apps designers. Also, for health information, how to integrate health data from various sources (such as CHITs and clinical HITs), how to filter health information based on personal needs, and how to evaluate health data quality, are worth considering.

\section{Conclusion}

This study contributes to the development of the current consumer health information technology (CHIT) research in IS by proposing a well-defined definition of CHIT and exploring the current state of CHIT research in IS. Our analysis of 176 CHIT papers published from 2000 to 2018 in eleven high-impact IS journals and three key IS conferences proceedings demonstrates the rapid growth of CHIT research in recent years. Most CHIT studies are presented in conferences, whereas only 36 papers are published in journals. We expect that more journal articles are likely forthcoming as conference papers make their way through the review process at journals. Regarding the research paradigm, $63 \%$ of the collected CHIT studies are behavioral science papers, while $37 \%$ of them are design science papers. According to the distribution results of CHIT research taking different IT views, there will likely be more representation of nominal, proxy, and tool views in journal articles as it does. For future work in this area, we offer some research directions for both behavioral science researchers and design science researchers to enrich the knowledge domain of CHIT.

\section{References}

[1] M. Cocosila and N. Archer, "Consumer Perceptions of the Adoption of Electronic Personal Health Records: An Empirical Investigation", Proceedings of the 18th Americas Conference on Information Systems, 2012, pp. 1-12.

[2] R. Rockmann and H. Gewald, "Technology-Mediated Health Activities: An Exploratory Study on Older Adults", Proceedings of the 22nd Americas Conference on Information Systems, 2016, pp. 1-10.

[3] R. Agarwal, G. Gao, C. DesRoches, and A.K. Jha, "Research Commentary - The Digital Transformation of Healthcare: Current Status and the Road Ahead”, Information Systems Research, 21(4), 2010, pp. 796-809.

[4] E. Davidson, A. Baird, and K. Prince, "Opening the envelope of health care information systems research", Information and Organization. 28(3), 2018, pp. 140-151.

[5] L. Otto, L. Harst, H. Schlieter, B. Wollschlaeger, P. Richter, and P. Timpel, “Towards a Unified Understanding of eHealth and Related Terms - Proposal of a Consolidated Terminological Basis”, Proceedings of the 11th International Joint Conference on Biomedical Engineering Systems and Technologies, 2018, pp. 533-539.

[6] M.C. Gibbons, R.F. Wilson, L. Samal, et al., Impact of Consumer Health Informatics Applications: Evidence Report/Technology Assessment, No. 188. Agency for Healthcare Research and Quality, Rockville, MD., 2009.

[7] A. Everard, K.St. Pierre, and J.L. Heck, "Contributors to the High-Impact IS Journals (1977-2014): An Aid for Setting Research Standards", Communications of the Association for Information Systems, 40, 2017, pp. 53-81.

[8] V. Braun and V. Clarke, "Using thematic analysis in psychology”, Qualitative Research in Psychology, 3(2), 2006, pp. 77-101.

[9] W.J. Orlikowski and C.S. Iacono, "Research Commentary: Desperately Seeking the 'IT' in IT ResearchA Call to Theorizing the IT Artifact”, Information Systems Research, 12 (2), 2001, pp. 121-134.

[10] J. Featherall, B. Lapin, A. Chaitoff, S.A. Havele, N. Thompson, and I. Katzan, "Characterization of Patient Interest in Provider-Based Consumer Health Information Technology: Survey Study”, Journal of Medical Internet Research, 20 (4), 2018, pp. 1-11.

[11] R.S. Valdez, T.M. Guterbock, K. Fitzgibbon, et al., "From loquacious to reticent: understanding patient health information communication to guide consumer health IT design", Journal of the American Medical Informatics Association, 24(4), 2017, pp. 680-696.

[12] J.L. Wolff, J.D. Darer, and K.L. Larsen, "Family Caregivers and Consumer Health Information Technology”, Journal of General Internal Medicine, 31(1), 2016, pp. 117121.

[13] C.K.L. Or and B.-T. Karsh, "A Systematic Review of Patient Acceptance of Consumer Health Information Technology”, Journal of the American Medical Informatics Association, 16(4), 2009, pp. 550-560.

[14] A. Hordern, A. Georgiou, S. Whetton, and M. Prgomet, "Consumer E-Health: An Overview of Research Evidence and Implications for Future Policy”, Health Information Management Journal, 40(2), 2011, pp. 6-14. 
[15] D. Tao, T. Wang, T. Wang, S. Liu, and X. Qu, "Effects of consumer-oriented health information technologies in diabetes management over time: a systematic review and meta-analysis of randomized controlled trials", Journal of the American Medical Informatics Association, 24(5), 2017, pp. 1014-1023.

[16] V.P. Cornet and R.J. Holden, "Systematic review of smartphone-based passive sensing for health and wellbeing", Journal of Biomedical Informatics, 77, 2018, pp. 120-132.

[17] R. Agarwal and J. Khuntia, Personal Health Information Management and the Design of Consumer Health Information Technology: Background Report. The Agency for Healthcare Research and Quality (AHRQ), Rockville, MD, 2009.

[18] R. Agarwal, C.L. Anderson, K. Crowley, and P. Kannan, Improving Consumer Health IT Application Development: Lessons from Other Industries Background Report. The Agency for Healthcare Research and Quality (AHRQ), Rockville, MD, 2011.

[19] A. Cawsey, F. Grasso, and C. Paris, "Adaptive Information for Consumers of Healthcare”, The Adaptive Web, 2007, pp. 465-484. Springer, Berlin, Heidelberg.

[20] F. Payton, G. Pare, C. Le Rouge, and M. Reddy, "Health Care IT: Process, People, Patients and Interdisciplinary Considerations", Journal of the Association for Information Systems, 12(2), 2011, pp. I-XIII.

[21] I. Benbasat and R.W. Zmud, "The Identity Crisis within the Is Discipline: Defining and Communicating the Discipline's Core Properties”, MIS Quarterly, 27(2), 2003, pp. 183-194.

[22] J. Webster and R.T. Watson, “Analyzing the Past to Prepare for the Future: Writing a Literature Review”, MIS Quarterly, 26(2), 2002, pp. xiii-xxiii.

[23] F. Bélanger and R.E. Crossler, "Privacy in the Digital Age: A Review of Information Privacy Research in Information Systems”, MIS Quarterly. 35(4), 2011, pp. 1017-1041.

[24] S.T. March and G.F. Smith, "Design and natural science research on information technology", Decision Support Systems, 15(4), 1995, pp. 251-266.

[25] A. Ilhan and M. Henkel, “10,000 Steps a Day for Health? User-based Evaluation of Wearable Activity Trackers”, Proceedings of the 51st Hawaii International Conference on Information System Sciences, 2018, pp.33773385.

[26] B. Choi, "Encouraging Active Lifestyle with Social Sharing: A Study on Mobile Fitness App”, Proceedings of the 39th International Conference on Information Systems, 2018, pp. 1-17.

[27] Z. Yan, T. Wang, Y. Chen, and H. Zhang, "Knowledge sharing in online health communities: A social exchange theory perspective”, Information \& Management, 53(5), 2016, pp. 643-653.

[28] F. Zahedi and J. Song, "Dynamics of Trust Revision: Using Health Infomediaries”, Journal of Management Information Systems, 24(4), 2008, pp. 225-248.

[29] A. Baird and T.S. Raghu, "Associating consumer perceived value with business models for digital services", European Journal of Information Systems, 24(1), 2015, pp. 4-22.
[30] A. Boonstra and M. van Offenbeek, "Towards consistent modes of e-health implementation: structurational analysis of a telecare programme's limited success", Information Systems Journal, 20(6), 2010, pp. 537-561.

[31] R. Klein, "An empirical examination of patientphysician portal acceptance”, European Journal of Information Systems, 16(6), 2007, pp. 751-760.

[32] J. Song and F. "Mariam" Zahedi, "Trust in health infomediaries”, Decision Support Systems, 43(2), 2007, pp. 390-407.

[33] T. Shimoda, "An interactive software-agent smoking cessation program”, Proceedings of the 36th Hawaii International Conference on Information System Sciences, 2003, pp. 1-9.

[34] D. Yim, J. Khuntia, S. Lim, and W. Duan, “To Ask or Not To Ask? An Investigation of User Engagement and Doctor-Seeking Decision in Online Health Infomediary", Proceedings of the 38th International Conference on Information Systems, 2017, pp. 1-18.

[35] X. Liu, X. Guo, H. Wu, and T. Wu, "The Impact of Individual and Organizational Reputation on Physicians' Appointments Online”, International Journal of Electronic Commerce, 20(4), 2016, pp. 551-577.

[36] H. Taiminen and K. Taiminen, "Usage of Facebook-and Anonymous Forum -- Based Peer Support Groups Online and Their Influence on Perceived Social Support Types in Weight Loss", Proceedings of the 49th Hawaii International Conference on Information System Sciences, 2016, pp. 3094-3103.

[37] H. Yang, X. Guo, and T. Wu, "Exploring the influence of the online physician service delivery process on patient satisfaction”, Decision Support Systems, 78, 2015 pp. 113121.

[38] L. Yan and Y. Tan, "Feeling Blue? Go Online: An Empirical Study of Social Support among Patients”, Information Systems Research, 25(4), 2014, pp. 690-709.

[39] S. Ba and L. Wang, "Digital health communities: The effect of their motivation mechanisms", Decision Support Systems, 55(4), 2013, pp. 941-947.

[40] J.-F. Chen, L.-L. Wu, and S.-C. Chou, "Effects of Journaling Dietary Intake App on the Health Outcomes of Chronic Kidney Disease Stage 3B-5", Proceedings of the 49th Hawaii International Conference on Information System Sciences, 2016, pp. 3379-3388.

[41] T. McCreless, "The Impact of Online Health Searches on Medical Outcomes: Some Evidence from Google Trends”, Proceedings of the 24th Americas Conference on Information Systems, 2018, pp. 1-8.

[42] E.V. Wilson and N.K. Lankton, "Demographic Trends in Consumer E-Health Adoption: Analysis of NCI HINTS 2003 and 2005 National Surveys”, Proceedings of the 15th Americas Conference on Information Systems, 2009, pp. 110.

[43] B. Tulu, D. Strong, S. Johnson, I. Bar-On, J. Trudel, and L. Garber, "Personal Health Records: Identifying Utilization Patterns from System Use Logs and Patient Interviews”, Proceedings of the 45th Hawaii International Conference on Information System Sciences, 2012, pp. 2716-2725.

[44] G. Kenny and R. Connolly, "Examining Citizens' Health Information Privacy Concerns: An Extension of the 
IPC Instrument”, Proceedings of the 23rd Americas Conference on Information Systems, 2017, pp. 1-10.

[45] C.L. Anderson and R. Agarwal, "The Digitization of Healthcare: Boundary Risks, Emotion, and Consumer Willingness to Disclose Personal Health Information", Information Systems Research, 22(3), 2011, pp. 469-490.

[46] R. Farzan and C. Jonassaint, "Exploring Dynamics of Facebook Health Support Groups: a Leadership Perspective”, Proceedings of the 50th Hawaii International Conference on Information System Sciences, 2017, pp.1- 10.

[47] C.M. Angst and R. Agarwal, "Adoption of Electronic Health Records in the Presence of Privacy Concerns: The Elaboration Likelihood Model and Individual Persuasion”, MIS Quarterly, 33(2), 2009, pp. 339-370.

[48] P. Nambisan, "Patient Portal Readiness (PPR) among the Underserved: Impact of PHIM Activities, Health Information Seeking, and Patient Attitudes towards Record Keeping”, Proceedings of the 48th Hawaii International Conference on Information System Sciences, 2015, pp. 2985-2991.

[49] M.Y. Yi, J.J. Yoon, J.M. Davis, and T. Lee, "Untangling the antecedents of initial trust in Web-based health information: The roles of argument quality, source expertise, and user perceptions of information quality and risk", Decision Support Systems, 55(1), 2013, pp. 284-295.

[50] M. Mpinganjira, "Precursors of trust in virtual health communities: A hierarchical investigation”, Information \& Management, 55(6), 2018, pp. 686-694.

[51] K.-Y. Huang, S. Chengalur-Smith, and A. Pinsonneault, "Why Should I Provide Social Support? A Social Capital Perspective of Individual Helping Behavior in Healthcare Virtual Support Communities”, Proceedings of the 35th International Conference on Information Systems, 2014, pp. $1-24$.

[52] L. Yan and Y. Tan, "The Consensus Effect in Online Health-Care Communities", Journal of Management Information Systems, 34(1), 2017, pp. 11-39.

[53] S. Kumar, T. Hanss, L. Johnson, et al., "Leveraging Contextual Inquiry Methods to Empower Patients in a Learning Health System”, Proceedings of the 48th Hawaii International Conference on Information System Sciences, 2015, pp. 3141-3147.
[54] A. Colley, K. Halttu, M. Harjumaa, and H. OinasKukkonen, "Insights from the Design and Evaluation of a Personal Health Dashboard", Proceedings of the 49th Hawaii International Conference on Information System Sciences, 2016, pp. 3483-3492.

[55] H. Liang, Y. Xue, and B.A. Berger, "Web-based intervention support system for health promotion”, Decision Support Systems, 42(1), 2006, pp. 435-449.

[56] L.U. Yoda, D. Nahl, and M.E. Crosby, "Stage-Based mHealth Communication Interventions for HPV Education”, Proceedings of the 46th Hawaii International Conference on Information System Sciences, 2013, pp. 2715-2724.

[57] M.F. Walji and J. Zhang, "Human-Centered Design of Persuasive Appointment Reminders”, Proceedings of the 41st Hawaii International Conference on Information System Sciences, 2008, pp. 236-236.

[58] O. Mujallid and S. Alghamdi, “ADR Reporting Through Twitter from Patient Perspective”, Proceedings of the 24th Americas Conference on Information Systems, 2018, pp. 1-8. [59] K. Lienhard and C. Legner, "The Anatomy of Contextaware Mobile Patient Monitoring”, Proceedings of the 36th International Conference on Information Systems, 2015, pp. $1-18$.

[60] Chunlan Ma, J. Warren, J. Staneck, and P. Phillips, “An Adaptive Profile Driven Consumer Education Web Portal for Diabetes”, Proceedings of the 38th Hawaii International Conference on Information System Sciences, 2005, pp. 1-10. [61] S.K. Lau, "Are Concerns and Needs of Parents Addressed? An Analysis of Cerebral Palsy Agencies Websites in Australia”, Proceedings of the 46th Hawaii International Conference on Information System Sciences, 2013, pp. 2425-2434.

[62] Y. Lu, P. Zhang, and S. Deng, "Exploring HealthRelated Topics in Online Health Community Using Cluster Analysis”, Proceedings of the 46th Hawaii International Conference on Information System Sciences, 2013, pp. 802811.

[63] C. LeRouge and J. Ma, "User Profiles and Personas in Consumer Health Technologies”, Proceedings of the 43rd Hawaii International Conference on Information System Sciences, 2010, pp. 1-10. 